
Not for reproduction, distribution or commercial use.

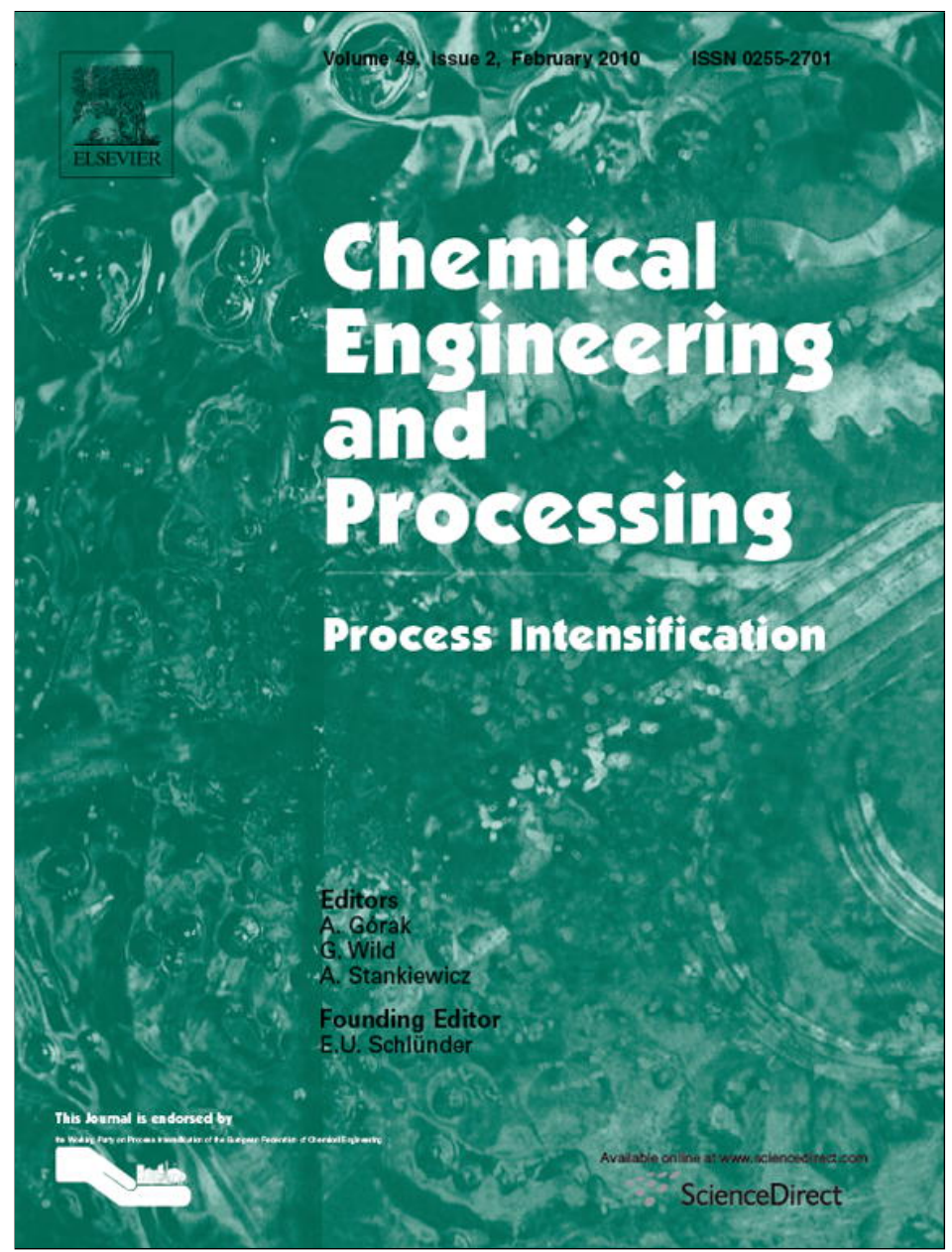

This article appeared in a journal published by Elsevier. The attached copy is furnished to the author for internal non-commercial research and education use, including for instruction at the authors institution and sharing with colleagues.

Other uses, including reproduction and distribution, or selling or licensing copies, or posting to personal, institutional or third party websites are prohibited.

In most cases authors are permitted to post their version of the article (e.g. in Word or Tex form) to their personal website or institutional repository. Authors requiring further information regarding Elsevier's archiving and manuscript policies are encouraged to visit:

http://www.elsevier.com/copyright 


\title{
Experimental study on pressure drops in a dividing wall distillation column
}

\author{
Fabricio Omar Barroso-Muñoz ${ }^{a}$, Salvador Hernández ${ }^{a}, *$, Héctor Hernández-Escoto ${ }^{a}$, \\ Juan Gabriel Segovia-Hernández ${ }^{a}$, Vicente Rico-Ramírez ${ }^{b}$, Rosa-Hilda Chavez ${ }^{c}$ \\ a Universidad de Guanajuato, Campus Guanajuato, Departamento de Ingeniería Química, Noria Alta s/n, Guanajuato, Gto. 36050, Mexico \\ ${ }^{\mathrm{b}}$ Instituto Tecnológico de Celaya, Departamento de Ingeniería Química, Av. Tecnológico y García Cubas s/n, Celaya, Gto. 38010, Mexico \\ ' Instituto Nacional de Investigaciones Nucleares, Carretera México-Toluca S/N, La Marquesa, Ocoyoacac, México 52750, Mexico
}

\section{A R T I C L E I N F O}

Article history:

Received 7 July 2009

Received in revised form 2 November 2009

Accepted 1 January 2010

Available online 7 January 2010

\section{Keywords:}

Dividing wall distillation column

Pressure drop

Energy savings

Pilot plant

\begin{abstract}
A B S T R A C T
Previous studies in the fields of process design and process control [1] have shown the potential benefits that can be achieved through the implementation of thermally coupled distillation sequences, in particular, the dividing wall distillation column. The dividing wall distillation column meets important goals of process intensification, including energy savings, reduction in carbon dioxide emissions and miniaturization. In this paper, an experimental study on the hydrodynamic behavior of a dividing wall distillation column is presented. Several different values for gas and liquid velocities were tested in order to measure pressure drops and identify operational regions; the air/water system was used as the basis for the experimental setup. Results regarding pressure drops (fitted to the model of Stichlmair et al.) provide operational limits for the operation of the packed dividing wall distillation column. According to the results, the experimental dividing wall column can be operated at turbulent regime that is associated to proper mass transfer.
\end{abstract}

(C) 2010 Elsevier B.V. All rights reserved.

\section{Introduction}

Both the design and the retrofit of chemical processes must take into account process intensification strategies. In the field of process separations, a good example of the application of the concept of process intensification is given by thermally coupled distillation. Thermally coupled distillation sequences for the separation of ternary mixtures are shown in Fig. 1. From among these sequences, the Petlyuk column (Fig. 2) has been implemented successfully in industrial practice using a single shell and a dividing wall [2].

A dividing wall distillation column can reduce energy consumption by $30-50 \%$ over conventional distillation sequences for the separation of some mixtures [3-6]. Furthermore, this reduction in energy consumption also results in lower carbon dioxide emissions and column diameter (miniaturization due to reduction in internal flows). Moreover, from theoretical analysis, it has been demonstrated that thermally coupled distillation sequences can present better theoretical control properties than conventional distillation schemes. It becomes clear then that the design or retrofit of thermally coupled distillation columns involves process intensification, i.e., reductions in energy consumption, reduction in carbon dioxide emissions and miniaturization without affecting proper operation. These benefits of thermally coupled distillation sequences have

\footnotetext{
* Corresponding author.

E-mail address: hernasa@quijote.ugto.mx (S. Hernández).
}

been obtained in industrial practice using the dividing wall distillation column (DWDC, Fig. 2). Such a complex distillation column is thermodynamically equivalent to the fully thermally coupled distillation column (Petlyuk column), but, in terms of analysis, it is easier to consider the Petlyuk distillation column.

Recently, additional aspects of process intensification have been taken into account in the field of distillation processes involving thermal links; for example, some theoretical studies have shown that the DWDC can be used to carry out reaction and separation in the same unit.

Previous work concerning the steady state design of the DWDC for ternary separations have explained that the energy savings achieved by this equipment are due to the side stream being extracted from the maximum in the composition profile of the intermediate component $[7,8]$. In addition, other studies have shown that energy consumption in the reboiler depends strongly on the values of the interconnecting flows of the DWDC [9]. Several advances have also been reported regarding dynamic behavior, where the main conclusion drawn is that the control of the DWDC is no more complicated than that of a conventional distillation column [10,11].

It is important to emphasize that most of the above referenced results are obtained using steady state and dynamic simulations considering the equilibrium stage model.

Regarding experimental studies, Kolbe and Wenzel [12] have simulated and validated their results using an experimental dividing wall distillation column. The agreement between the predicted 


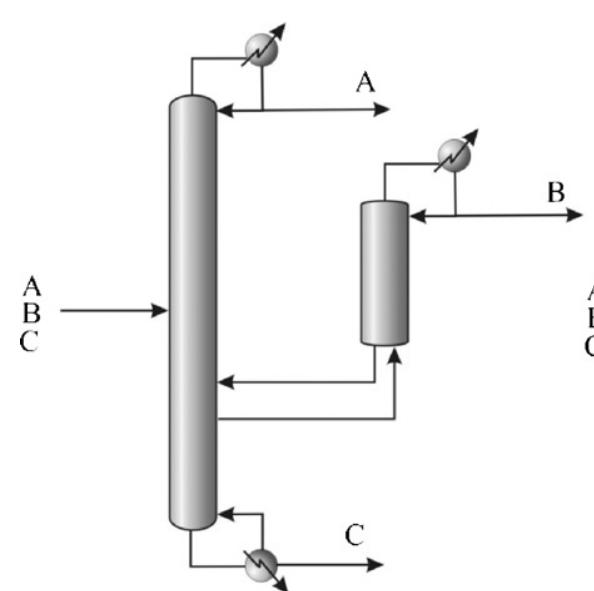

(a) TCDS-SR

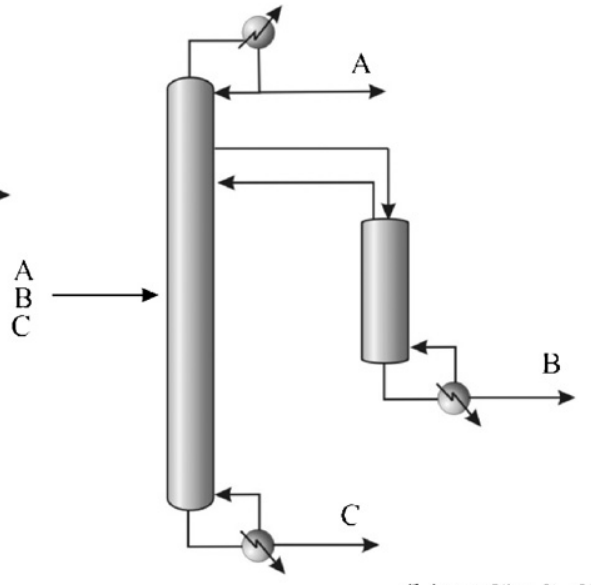

(b) TCDS-SS

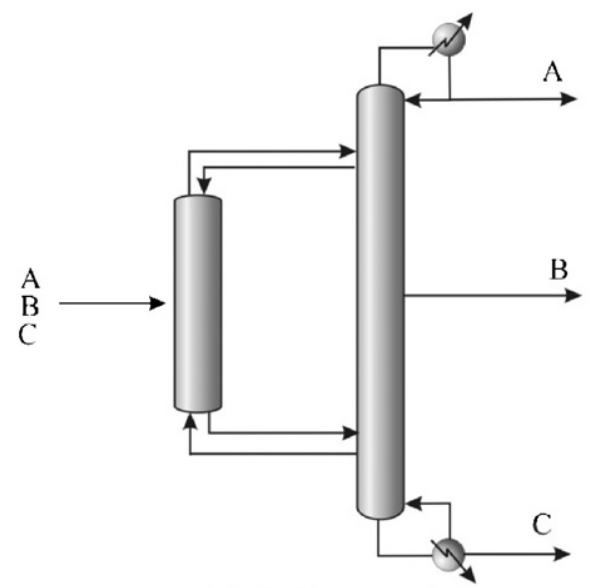

(c) Petlyuk column

Fig. 1. Thermally coupled distillation options for ternary separations: (a) direct thermally coupled distillation sequence (TCDS-SR), (b) indirect thermally coupled distillation sequence (TCDS-SS), and (c) Petlyuk distillation column.

and experimental temperature profiles was extremely good. As a result, they concluded that proper operation of the dividing wall distillation column can be achieved without difficulties. In order to support the practical implementation and operation of the dividing wall distillation column, the control was investigated [13] using a classical proportional plus integral controller and the model predictive control. Results indicated that the model predictive controller presented better dynamic responses in terms of deviations on the controller variables and times required to achieve the changes in set points.

Sander et al. [14] have studied the hydrolysis of the methyl acetate in a dividing wall distillation column using simulation and experimental tests. They found good agreement between the theoretical studies and the experimental results, concluding that it is

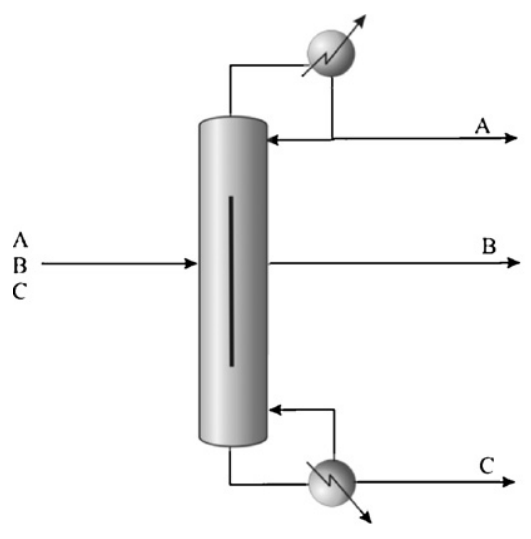

(a)

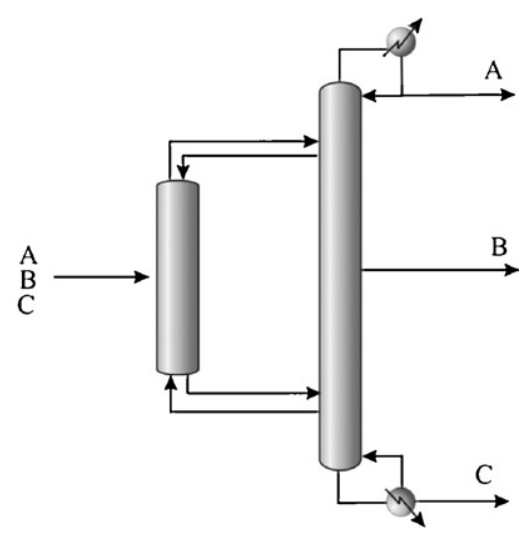

(b)

Fig. 2. (a) Dividing wall distillation column and (b) Petlyuk column. 
possible to carry out some chemical reactions in the dividing wall distillation columns when the product of the reactive distillation is the intermediate boiling component. It is important to highlight that their experimental tests were carried in a mini plant, implemented using parallel tubes of inner diameters between 4 and $5.5 \mathrm{~cm}$, and an industrial dividing wall distillation column with an inner diameter of $0.22 \mathrm{~m}$.

Other works regarding simulations of the dividing wall distillation columns have been reported using a stage model based on mass transfer equations. For instance, Muller and Kening [15] have simulated the dividing wall distillation column considering reactive and non-reactive cases, and they found that the composition and temperature profiles showed good agreement with those measured in a DWDC.

Recently, the first industrial implementation of a reactive dividing wall distillation column has been reported by Akzo Nobel Chemicals [16] for the recovery of an intermediate by-product that became more important that the main product. Also, it was found that savings of 35 and $15 \%$ in capital and energy costs, respectively, were obtained.

According to open literature [2], dividing wall distillation columns of up to $6 \mathrm{~m}$ of diameter and $100 \mathrm{~m}$ of height are being implemented.

As a complement, the main objective of this work is the study of the hydrodynamic behavior of an experimental packed DWDC. Although our experimental apparatus was designed to carry out the esterification reaction between acetic acid and ethanol using sulphuric acid as catalyst, the air/water system is used as the basis for our analysis in this paper. Results of this study can then be applied to identify operational regimes, because it is only through an appropriate operation of the column that the process intensification objectives are achieved.

\section{Hydrodynamic model}

The experimental study of the hydrodynamic behavior of packed distillation columns plays an important role in identifying operational regions. Such study helps to prevent operational and control problems. Operational regions are determined by the capacity of the distillation column to handle different internal flows of liquid and vapor while avoiding significant pressure drops. In the case of packed distillation towers, capacity and pressure drop depend on both the packing and the internals $[17,18]$. We stress the importance of understanding hydrodynamic behavior in the operation of the intensified DWDC, since it has been reported that, in many cases, the estimation of the maximum hydraulic capacity and pressure drop for a given packing can be used for design purposes [19]. Also, the identification of the loading point in a packed bed is important [20], since this point is associated to good distribution of liquid through the packed bed and turbulence in the vapor and liquid phases, promoting an increment in the efficiency of mass transfer.

Several models can be used to calculate pressure drops, including the model reported by Stichlmair et al. [21], which takes into account internal flows and characteristics of packings. Eqs. (1)-(3) represent the model of Stichlmair et al. [21].

$$
\begin{aligned}
\frac{\Delta p_{i r r}}{\rho_{L} g Z}= & \frac{\Delta p_{d r y}}{\rho_{L} g Z} \frac{\left\{1-\varepsilon\left[1-\left(h_{0} / \varepsilon\right)\left[1+20\left(\Delta p_{i r r} / \rho_{L} g Z\right)^{2}\right]\right]\right\}}{1-\varepsilon} \\
& \times\left[1-\frac{h_{0}}{\varepsilon}\left[1+20\left(\frac{\Delta p_{i r r}}{\rho_{L} g Z}\right)^{2}\right]\right]^{-4.65}
\end{aligned}
$$

$C=\frac{\left(-c_{1} / \operatorname{Re}_{G}\right)-\left(c_{2} / 2 R e_{G}^{0.5}\right)}{f_{0}}$

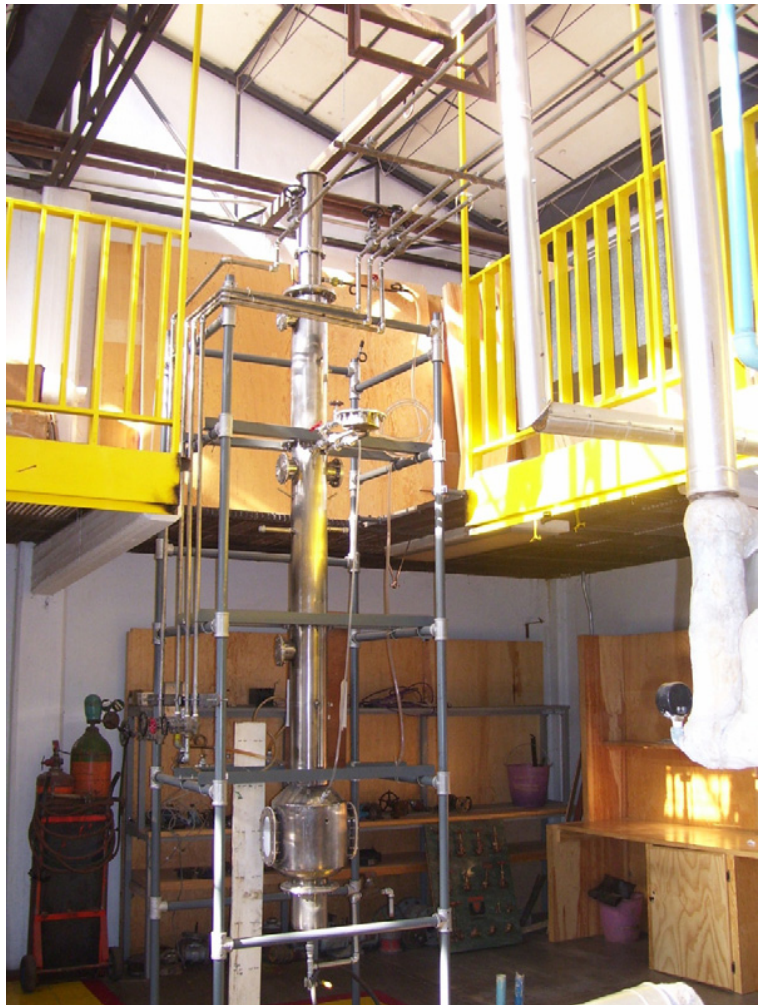

Fig. 3. Experimental DWDC

$f_{0}=\frac{c_{1}}{R e_{G}}+\frac{c_{2}}{R e_{G}^{0.5}}+c_{3}$

where $\Delta P_{\text {irr }}$ is the pressure drop per unit of height of packed section $(\mathrm{Pa} / \mathrm{m}), \rho_{L}$ and $\rho_{G}$ are the liquid and gas densities, respectively $\left(\mathrm{kg} / \mathrm{m}^{3}\right), g$ is the gravitational constant $\left(\mathrm{m} / \mathrm{s}^{2}\right), Z$ is the total height of the packed section under study $(\mathrm{m}), \varepsilon$ is the void fraction $\left(\mathrm{m}^{3} / \mathrm{m}^{3}\right)$, $h_{0}$ is the hold up in the charge region per packing unit volume $\left(\mathrm{m}^{3} / \mathrm{m}^{3}\right), c, c_{1}, c_{2}$ and $c_{3}$ are constants, $R e_{G}$ is the Reynolds number for the gas, and $f_{0}$ is the particle friction factor. Constants $c_{1}, c_{2}$ and $c_{3}$ are reported for some commercial packings [21,22], but these constants can be determined experimentally for non-commercial packings. Hence, the model given by Eqs. (1) through (3) is considered in this work as the basis for the representation of pressure drop behavior in the DWDC.

\section{Description of the DWDC}

The experimental DWDC is shown in Fig. 3. Fig. 4 depicts its main components. The experimental DWDC has three sections packed with Teflon Raschig rings with diameter of $20 \mathrm{~mm}$ (see Fig. 4); these sections are numbered starting with the upper section. Because we are interested in hydrodynamic behavior, below we describe the functionality of each of the main components and their role in such a behavior.

The reflux flowrate enters the first distributor tray located at the top of the first packed section (Fig. 4). The goal of this internal device is the uniform distribution of the liquid flow in this section. The first packed section is a conventional packed section with a collector tray at the bottom.

The second packed section plays an important role in the proper operation of the DWDC, since it contains an interior wall, which divides the column in two packed sections (see Fig. 4).

The position of this wall is used to set the flows of vapor to both of its sides. In terms of conceptual design, this wall allows the inclu- 


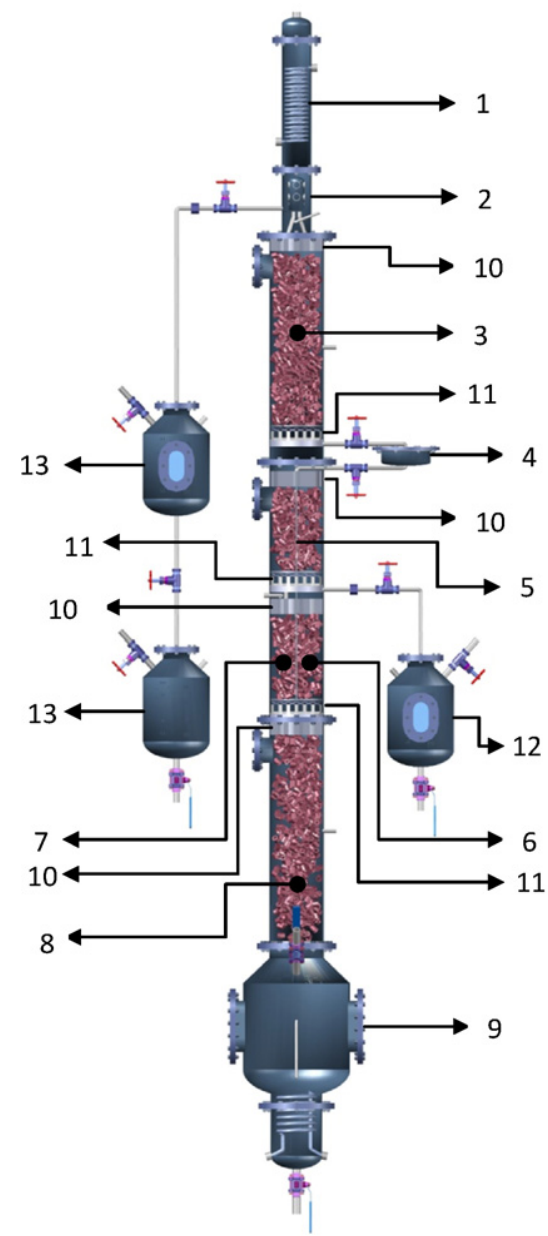

$\begin{array}{ll}1 & \text { Condenser } \\ 2 & \text { Reflux valve } \\ 3 & \text { First packed section } \\ 4 & \text { Side tank splitter } \\ 5 & \text { Dividing wall } \\ 6 & \text { Second packed section (side product) } \\ 7 & \text { Second packed section ( feed) } \\ 8 & \text { Third packed section } \\ 9 & \text { Reboiler } \\ 12 & \text { Side product collector } \\ 13 & \text { Side tanks for distillate } \\ 10 & \text { Distributor tray } \\ 11 & \text { Collector tray }\end{array}$

Fig. 4. Components of the DWDC.

sion of the prefractionator inside the middle section of the Petlyuk distillation column in a single shell. For the second section, the liquid from the first section must be divided and directed to both sides. To achieve that, the flow from the upper section is collected by a side tank (Fig. 4), where it is divided using two valves to obtain the two required flows; such flows are then returned to the middle section. These two liquid flows are very important, because it has been demonstrated that energy consumption depends on their values.

The liquid that leaves the bottom part of the middle packed section is sent to a tray distributor located in the upper section of the third packed section. Finally, the liquid that leaves the third packed section is collected in the reboiler shown in Fig. 4.

The DWDC contains thermocouples and manometers to take measurements at different points of the column.

\section{Experimental setup}

Energy optimization of the DWDC has already been reported in Hernández et al. [1] and it is shown in Fig. 5. This energy optimization corresponds to the reaction between ethanol and acetic acid using sulphuric acid as catalyst to yield ethyl acetate and water.

It can be noted that energy consumption depends strongly on the values assigned to the interconnecting flows. According to results for a reactive DWDC [1], the manipulation of the interconnecting vapor flow is more difficult than the manipulation of the interconnecting liquid stream. This has been accounted for by using a side tank for external manipulation of the liquid. It is important to note that reduction in energy consumption achieved through manipulation of interconnecting streams is associated to the internal flows that determine the diameter of the distillation column.

At this point, it is important to mention that the dividing wall distillation column was designed for the specific reaction between the acetic acid and ethanol to produce ethyl acetate and water, but the experimental study of the hydrodynamic is conducted for the

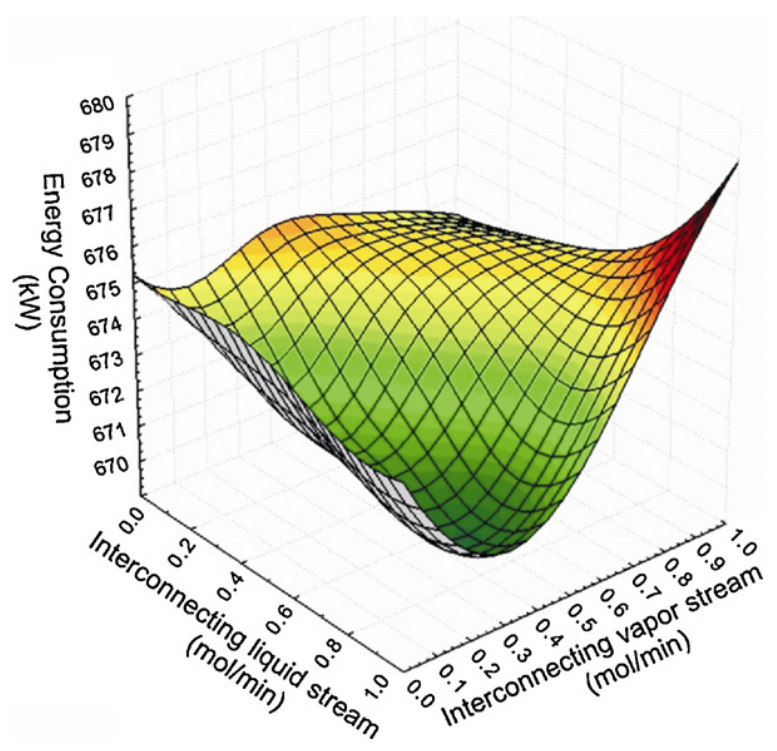

Fig. 5. Energy optimization of the reactive dividing wall column. 


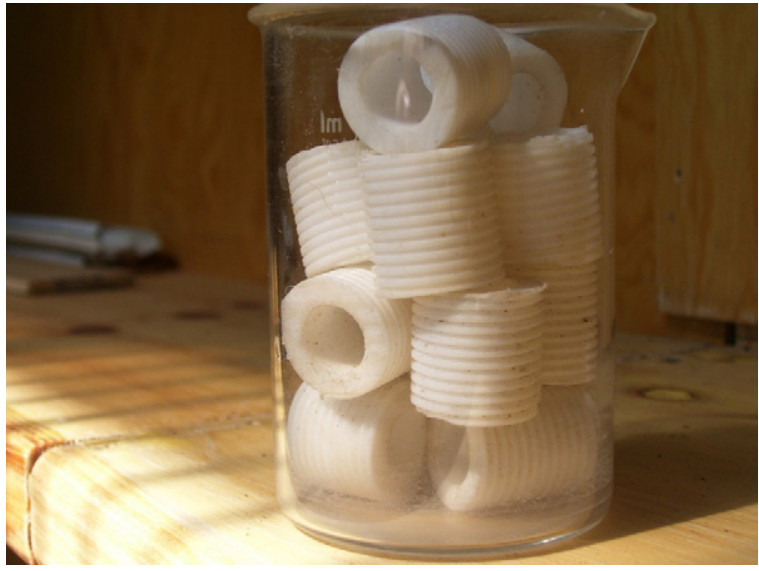

Fig. 6. Modified Teflon ${ }^{\mathrm{TM}}$ Raschig rings.

air/water system. This implies that the actual column works like a dividing wall distillation column.

In order to conduct the experimental test, packing characteristics were first determined. Considering that the diameter and height of the packed bed of the experimental dividing wall distillation column are 0.17 and $2 \mathrm{~m}$, respectively, a packing with external diameter of $20 \mathrm{~mm}$ was fabricated using Teflon ${ }^{\mathrm{TM}}$ hollow tubes. Because, our future goal is carrying out esterification reactions catalyzed by sulphuric acid, the fabricated packings do not act as catalytic packings.

The size of the packing was set according to the ratio of packing diameter to column diameter recommended by Kister [23] to reduce liquid maldistribution (1/10-1/8). The packing shown in Fig. 6 has values of $177.249 \mathrm{~m}^{2} / \mathrm{m}^{3}$ and 0.67 for specific area and void fraction, respectively. The conditions for the experimental procedure were ambient pressure of $0.8 \mathrm{~atm}$ and temperature of $298 \mathrm{~K}$.

\section{Hydrodynamic behavior: pressure drop and operational limits}

Experimental pressure drops were measured for different liquid and gas loads using the system air/water. These experimental values were fitted to the hydrodynamic model proposed by Stichlmair et al. [21] to obtain the unknown parameters for this noncommercial packing, as mentioned previously. Table 1 presents the values for these parameters, and Fig. 7 presents pressure drop calculated and experimental pressure measured for a liquid velocity of $0.00129 \mathrm{~m} / \mathrm{s}$. Fig. 8 shows a comparison among the experimental and predicted values for the various tests, where we observe that experimental values are similar to those predicted. Also, Fig. 8 shows that the experimental DWDC can be operated at turbulent regime, promoting proper mass transfer during the operation.

As an important result, the operational limits of the column were determined. The DWDC can handle gas velocities up to $1.1 \mathrm{~m} / \mathrm{s}$, and liquid velocities of up to $0.0057 \mathrm{~m} / \mathrm{s}$.

This study of hydrodynamic behavior of the DWDC is also important in order to set the operational limits of reflux rate and boil-up rate during operation including an equilibrium reaction in the

Table 1

Parameters used in the model of Stichlmair et al. [12].

\begin{tabular}{ll}
\hline Parameter & Value \\
\hline$C_{1}$ & 227.2059 \\
$C_{2}$ & -1.8497234 \\
$C_{3}$ & 0.23663 \\
\hline
\end{tabular}

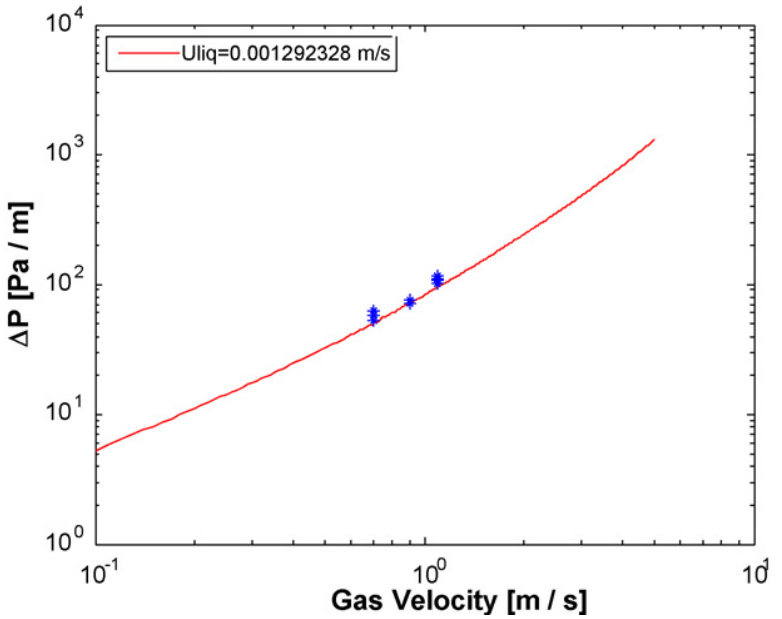

Fig. 7. Pressure drop for liquid velocity of $0.00129 \mathrm{~m} / \mathrm{s}$.

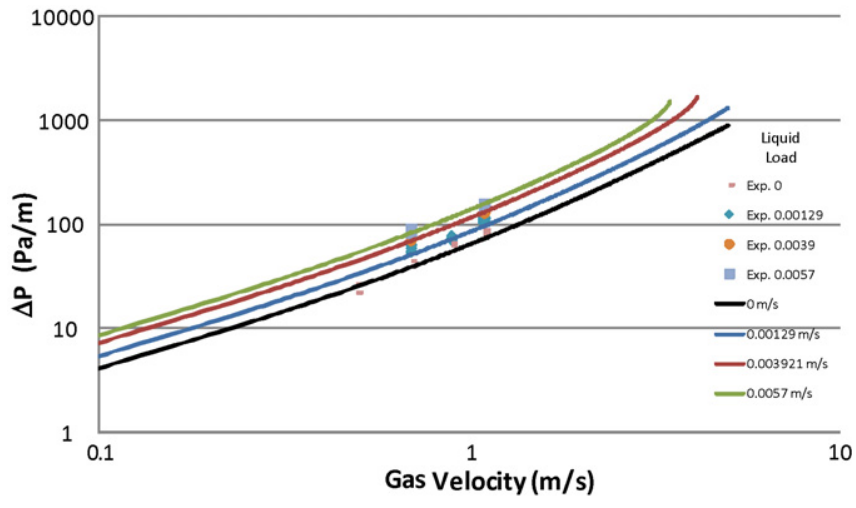

Fig. 8. Pressure drop for several liquid velocity values.

reboiler avoiding high pressure drop. Finally, we want to emphasize that, although the air/water system is not a realistic industrial case, the results obtained can be used for the generation of open information that can be applied to the operation of DWDCs. In fact, the information is currently being used in the operation and monitoring of a reactive case in the instrumented DWDC.

\section{Conclusions}

The experimental hydrodynamic behavior of a DWDC was studied. The results indicate that pressure drops for several flows of liquid and gas can be adjusted by the model of Stichlmair et al. [21]. This adjusted model can be used to predict operational regions of the distillation column. Moreover, the regions determined by hydrodynamic study can be used to avoid operational problems in the manipulation of reflux rate and steam supplied to the reboiler during operation. Finally, the turbulent regime detected in the operation can promote proper mass transfer.

\section{Acknowledgements}

We acknowledge the financial support provided by Universidad de Guanajuato, CONACyT and CONCyTEG (Mexico).

\section{References}

[1] S. Hernández R Sandoval-Vergara, F. B Barroso-Muñoz R. Murrieta-Dueñas, H. Hernández-Escoto, J.G. Segovia-Hernández, V. Rico-Ramírez, Reactive dividing wall distillation columns: simulation and implementation in a pilot plant, Chem. Eng. Process. 48 (2009) 250. 
[2] Z. Olujic, M. Jödecke, A. Shilkin, G. Schuch, B. Kaibel, Equipment improvement trends in distillation, Chem. Eng. Process. 48 (2009) 1089.

[3] Z. Olujic, B. Kaibel, H. Jansen, T. Rietfort, E. Zich, G. Frey, Distillation column internals/configurations for process intensification, Chem. Biochem. Eng. Q. 17 (2003) 301.

[4] S. Hernández, A. Jiménez, Design of energy-efficient Petlyuk systems, Comput. Chem. Eng. 23 (1999) 1005

[5] I. Malinen, J. Tanskanen, Thermally coupled side-column configurations enabling distillation boundary crossing. 1. An overview and a solving procedure, Ind. Eng. Chem. Res. 48 (2009) 6387.

[6] I. Malinen, J. Tanskanen, Thermally coupled side-column configurations enabling distillation boundary crossing. 2 . Effects of intermediate heat exchangers, Ind. Eng. Chem. Res. 48 (2009) 6372.

[7] C. Triantafyllou, R. Smith, The design and optimisation of fully thermally coupled distillation columns, Trans. Inst. Chem. Eng. Part A 70 (1992) 118.

[8] S. Hernández, J.G. Segovia-Hernández, V. Rico-Ramírez, Thermodynamically equivalent distillation schemes to the Petlyuk column for ternary mixtures, Energy 31 (2006) 1840

[9] M. Serra, A. Espuña, L. Puigjaner, Controllability of different multicomponent distillation arrangements, Ind. Eng. Chem. Res. 42 (2003) 1773.

[10] S. Hernández, A. Jiménez, Controllability analysis of thermally coupled distillation systems, Ind. Eng. Chem. Res. 38 (1999) 3957.

[11] S.J. Wang, D. Wong, Controllability and energy efficiency of a high purity divided wall column, Chem. Eng. Sci. 62 (2007) 1010.

[12] B. Kolbe, S. Wenzel, Novel distillation concepts using one-shell columns, Chem. Eng. Process. 43 (2004) 339.
[13] T. Adrian, H. Schoenmakers, M. Boll, Model predictive control of integrated unit operations: control of a divided wall column, Chem. Eng. Process. 43 (2004) 347.

[14] S. Sander, C. Flisch, E. Geissler, H. Schoenmakers, O. Ryll, H. Hasse, Methyl acetate hydrolysis in a reactive divided wall column, Chem. Eng. Res. Des. 85 (2007) 149.

[15] I. Muller, E.Y. Kenig, Reactive distillation in a dividing wall column: rate-based modeling and simulation, Ind. Eng. Chem. Res. 46 (2007) 3709.

[16] A.A. Kiss, J.J. Pragt, C.J.G. Van Strien, Reactive dividing-wall columns-how to get more with less resources, Chem. Eng. Commun. 196 (2009) 1366.

[17] A. Rix, Z. Olujic, Pressure drop of internals for packed columns, Chem. Eng. Process. 47 (2008) 1520

[18] A.F. Seibert, J.C. Lewis, J.R. Fair, Liquid-continuous distillation, Ind. Eng. Chem. Res. 47 (2008) 4290.

[19] J. Uresti-Meléndez, J.A. Rocha, Pressure drop in ceramic structured packings, Ind. Eng. Chem. Res. 32 (1993) 2247.

[20] H.-J. Verschoof, Z. Olujic, J.R. Fair, A generalized correlation for predicting the loading point of corrugated sheet structured packings, Ind. Eng. Chem. Res. 38 (1999) 3663.

[21] J. Stichlmair, J.L. Bravo, J.R. Fair, General model for prediction of pressure drop and capacity of countercurrent gas/liquid packed columns, Gas Sep. Purif. 3 (1989) 19.

[22] J. Stichlmair, J.R. Fair, Distillation: Principles and Practice, 1st ed., Wiley-VCH, New York, 1998.

[23] H.Z. Kister, Distillation Design, 1st ed., Mc Graw Hill, New York, 1992. 